\title{
Optimal use of $\beta$-blockers in high-risk hypertension: A guide to dosing equivalence
}

This article was published in the following Dove Press journal:

Vascular Health and Risk Management

14 May 2010

Number of times this article has been viewed

\section{Janet B McGill}

Department of Medicine, Washington University School of Medicine,

St. Louis, Missouri, USA
Correspondence: Janet B McGil

Washington University School of Medicine, 660 South Euclid Avenue, Campus Box 8I27, St. Louis, MO 63।I0, USA

$\mathrm{Tel}+\mathrm{I} 3 \mid 4362868$ I

Fax + I 3143624833

Email jmcgill@im.wustl.edu
Abstract: Hypertension is the number one diagnosis made by primary care physicians, placing them in a unique position to prescribe the antihypertensive agent best suited to the individual patient. In individuals with diabetes mellitus, blood pressure (BP) levels $>130 / 80 \mathrm{mmHg}$ confer an even higher risk for cardiovascular and renal disease, and these patients will benefit from aggressive antihypertensive treatment using a combination of agents. $\beta$-blockers are playing an increasingly important role in the management of hypertension in high-risk patients. $\beta$-blockers are a heterogeneous class of agents, and this review presents the differences between $\beta$-blockers and provides evidence-based protocols to assist in understanding dose equivalence in the selection of an optimal regimen in patients with complex needs. The clinical benefits provided by $\beta$-blockers are only effective if patients adhere to medication treatment long term. $\beta$-blockers with proven efficacy, once-daily dosing, and lower side effect profiles may become instrumental in the treatment of hypertensive diabetic and nondiabetic patients.

Keywords: antihypertensive, blood pressure, atenolol, carvedilol, labetalol, metoprolol, nebivolol

\section{Introduction}

Hypertension is one of the most common reasons for primary care physician visits and the number one diagnosis during appointments. ${ }^{1}$ Approximately 65 million Americans have hypertension, with a marked increase in prevalence among younger adults aged 18-39 years, which may be related to the high obesity incidence in this country. ${ }^{2,3}$ The Joint National Committee on Prevention, Detection, Evaluation, and Treatment of High Blood Pressure (JNC) guidelines are evidence-based recommendations that integrate epidemiologic and clinical trial evidence about the health benefits associated with antihypertensive therapies into patient management decisions. ${ }^{4}$ The most recent $\mathrm{JNC}$ guidelines (JNC7) recommend maintaining a target blood pressure (BP) of $<140 / 90 \mathrm{mmHg}$ in patients with hypertension to reduce heart disease risk. ${ }^{5}$ To achieve BP control, the majority of patients with hypertension will need at least two medications from different pharmacologic classes. Patients with compelling indications such as heart failure (HF), myocardial infarction (MI), high coronary disease risk, and diabetes may need more aggressive treatment with three agents (Table 1$)^{5}$

Of particular concern is the patient with concomitant diabetes or who is at high risk for diabetes. Patients with both hypertension and diabetes have a dramatically increased risk for cardiovascular complications, such as stroke and chronic kidney disease. ${ }^{6}$ Data from clinical studies emphasize the need for tight BP control in these patients. In the 
Table I Clinical trial and guideline basis for compelling indications for individual drug classes

\begin{tabular}{|c|c|c|c|c|c|c|c|}
\hline $\begin{array}{l}\text { High-risk condition } \\
\text { with compelling } \\
\text { indication }^{\mathrm{a}}\end{array}$ & $\begin{array}{l}\text { Thiazide-type } \\
\text { diuretic }\end{array}$ & $\beta$-Blocker & ACEI & ARB & ССВ & Ald Ant & $\begin{array}{l}\text { Guideline and/or } \\
\text { clinical trial basis }^{\mathrm{b}}\end{array}$ \\
\hline Heart failure & $x$ & $x$ & $x$ & $x$ & & $x$ & $\begin{array}{l}\text { ACC/AHA heart failure } \\
\text { guidelines, MERIT-HF, } \\
\text { COPERNICUS, CIBIS, } \\
\text { SOLVD, AIRE,TRACE, } \\
\text { Val-HeFT, RALES, } \\
\text { CHARM }\end{array}$ \\
\hline $\begin{array}{l}\text { Post-myocardial } \\
\text { infarction }\end{array}$ & & $x$ & $x$ & & & $x$ & $\begin{array}{l}\text { ACA/AHA post- } \\
\text { myocardial infarction } \\
\text { guidelines, BHAT, SAVE, } \\
\text { CAPRICORN, EPHESUS }\end{array}$ \\
\hline $\begin{array}{l}\text { High coronary } \\
\text { disease risk }\end{array}$ & $x$ & $x$ & $x$ & & $x$ & & $\begin{array}{l}\text { ALLHAT, HOPE, ANBP2, } \\
\text { LIFE, CONVINCE, } \\
\text { EUROPA, INVEST }\end{array}$ \\
\hline Diabetes & $\mathrm{X}$ & $x$ & $x$ & $x$ & $x$ & & $\begin{array}{l}\text { NKF-ADA Guidelines, } \\
\text { UKPDS, ALLHAT }\end{array}$ \\
\hline Chronic kidney disease & & & $x$ & $x$ & & & $\begin{array}{l}\text { NKF Guidelines, } \\
\text { Captopril Trial, RENAAL, } \\
\text { IDNT, REIN,AASK }\end{array}$ \\
\hline $\begin{array}{l}\text { Recurrent stroke } \\
\text { prevention }\end{array}$ & $x$ & & $x$ & & & & PROGRESS \\
\hline
\end{tabular}

Notes: ${ }^{a}$ Compelling indications for antihypertensive drugs are based on benefits from outcome studies or existing clinical guidelines; the compelling indication is managed in parallel with the BP. ${ }^{b}$ Conditions for which clinical trials demonstrate benefit of specific classes of antihypertensive drugs used as part of an antihypertensive regimen to achieve BP goal to test outcomes.

Copyright $@$ 2003. Adapted with permission from Chobanian AV, Bakris GL, Black HR, et al. Seventh report of the Joint National Committee on Prevention, Detection, Evaluation, and Treatment of High Blood Pressure. Hypertension. 2003;42(6): 1206-1252.

Abbreviations: AASK, African-American Study of Kidney Disease and Hypertension; ACC/AHA, American College of Cardiology/American Heart Association; ACEI, angiotensin-converting enzyme inhibitor; AIRE, Acute Infarction Ramipril Efficacy; Ald Ant, aldosterone antagonist; ALLHAT, Antihypertensive and Lipid Lowering Treatment to Prevent Heart Attack Trial; ANBP2, Second Australian National Blood Pressure Study; ARB, angiotensin receptor blocker; BHAT, Beta-Blocker Heart Attack Trial; CAPRICORN, Carvedilol Post-Infarct Survival Control in Left Ventricular Dysfunction; CCB, calcium channel blocker; CIBIS, Cardiac Insufficiency Bisoprolol Study; CONVINCE, Controlled Onset Verapamil Investigation of Cardiovascular Endpoints; COPERNICUS, Carvedilol Prospective Randomized Cumulative Survival; EPHESUS, Eplerenone Post-Acute Myocardial Infarction Heart Failure Efficacy and Survival Study; EUROPA, European Trial on Reduction of Cardiac Events with Perindopril in Stable Coronary Artery Disease; HOPE, Heart Outcomes Prevention Evaluation; IDNT, Irbesartan in Diabetic Nephropathy Trial; INVEST, International Verapamil SR/Trandolapril Study; LIFE, Losartan Intervention for Endpoint Reduction; MERIT-HF, Metoprolol CR/XL Randomised Intervention Trial in Congestive Heart Failure; NKF-ADA, National Kidney Foundation-American Diabetes Association; PROGRESS, Perindopril Protection Against Recurrent Stroke Study; RALES, Randomized Aldactone Evaluation Study; REIN, Ramipril Efficacy in Nephropathy; RENAAL, Reduction in End Points in Noninsulin-Dependent Diabetes Mellitus with the Angiotensin II Antagonist Losartan; SAVE, Survival and Ventricular Enlargement; SOLVD, Studies of Left Ventricular Dysfunction;TRACE, Trandolapril Cardiac Evaluation; UKPDS, UK Prospective Diabetes Study; Val-HeFT, Valsartan in Heart Failure Trial.

UK Prospective Diabetes Study (UKPDS), 1,148 patients with type 2 diabetes and hypertension were randomized to more intense or less intense BP control and achieved BPs of 144/82 and 154/87 $\mathrm{mmHg}$, respectively, using either an angiotensin-converting enzyme inhibitor (ACEI) or a $\beta$-blocker. ${ }^{7}$ Patients assigned to more intense BP control experienced risk reductions of $24 \%$ in diabetes-related endpoints, $32 \%$ in diabetes-related deaths, $44 \%$ in stroke, $56 \%$ in $\mathrm{HF}$, and $37 \%$ in microvascular endpoints. Treatment with either ACEIs or $\beta$-blockers substantially reduced the risk of death and diabetes-related complications. ${ }^{7,8}$

For patients with hypertension and diabetes, national organizations such as the National Kidney Foundation (NKF), American Diabetes Association (ADA), American Association of Clinical Endocrinologists (AACE), and the JNC recognize the serious risk and recommend BP control to $<130 / 80 \mathrm{mmHg}$. ${ }^{5,-11}$ Although national guidelines emphasize the importance of maintaining BP control in people with hypertension, it has been reported that only $33 \%$ of physicians consider clinical practice guidelines as important for providing optimal disease management. ${ }^{12}$ Moreover, only $25 \%-36 \%$ of all patients with hypertension reach target BP goals, although with intensive medication monitoring and titration up to $69 \%$ of patients may maintain BP control. ${ }^{13-16}$ An analysis of data from The National Health and Nutrition Examination Survey (NHANES) 1988 to 2000 found that $<30 \%$ of patients with diabetes achieved their target BP $(<130 / 85 \mathrm{mmHg}){ }^{16}$ The American College of Physicians recommends initiating antihypertensive therapy with a thiazide diuretic or an ACEI in patients with hypertension 
and diabetes. ${ }^{17}$ In most cases, however, additional agents are required to achieve BP goals. ${ }^{5,18}$ Indeed, patients who are $>20 / 10 \mathrm{mmHg}$ above their BP goal should initiate treatment with two antihypertensive agents that have complementary mechanisms in order to reach target BP and reduce cardiovascular risk. $^{5}$

The NKF, ADA, AACE, and JNC7 all include a recommendation for the use of $\beta$-blockers., ${ }^{5-11}$ Several randomized controlled trials and meta-analyses have shown that when monotherapy is used for essential hypertension, $\beta$-blockers and diuretics are equally effective at lowering BP compared with ACEIs, adrenergic receptor binders (ARBs), and calcium channel blockers (CCBs). ${ }^{19-25}$ Patients with hypertension and compelling indications such as HF or diabetes may benefit from treatment with $\beta$-blockers because they have antiatherogenic, antiarrhythmic, and anti-ischemic properties. ${ }^{26-28}$ Clinical trials have demonstrated the beneficial effects of $\beta$-blockers in patients with coronary heart disease, post-MI patients, and patients with diabetes. ${ }^{8,29-32}$

\section{$\beta$-blockers for treatment of hypertension}

There is a need to improve hypertension management in high-risk patients, and optimal therapy choice may enhance both adherence and outcomes in the long term. Despite their proven cardiovascular benefits, $\beta$-blockers are underused for the treatment of hypertension in patients with diabetes because of their perceived side effect profile. ${ }^{8,33,34}$ However, various agents within the class of $\beta$-blockers have different pharmacologic properties, including receptor antagonism effects, resulting in variable clinical outcomes in terms of hemodynamic and metabolic effects and tolerability across the spectrum of cardiovascular diseases. ${ }^{35-40}$

Concerns about the use of $\beta$-blockers as first-line agents for hypertension have been raised because of a 2005 metaanalysis that found $\beta$-blockers do not significantly reduce cardiovascular events, especially stroke, compared with other antihypertensive drug classes. ${ }^{41}$ However, atenolol was the $\beta$-blocker evaluated in three quarters of the studies included in this meta-analysis (the others were propranolol, oxprenolol, metoprolol, and pindolol). Atenolol does not reduce all-cause mortality in hypertension long term compared with other agents. ${ }^{41}$ Another meta-analysis of five randomized controlled trials with more than 17,000 patients found significantly higher mortality (relative risk $[\mathrm{RR}]=1.13,95 \%$ confidence interval $[\mathrm{CI}]=1.02,1.25)$ with atenolol compared with other agents. $^{22}$ These analyses raise questions about whether atenolol is suitable for high-risk patients with hypertension.

Atenolol, metoprolol ( $\beta 1$-selective blockers), and propranolol (a $\beta 1$-, $\beta 2$-blocker) are associated with decreased insulin sensitivity and lipid metabolism..$^{35,41,42}$ However, the third-generation nonselective $\beta$-blocker carvedilol does not have a negative effect on glycemic control and has an overall neutral effect on lipids. ${ }^{35,42,43}$ Similar effects on metabolic parameters have been observed with nebivolol in patients with hypertension and diabetes. ${ }^{44}$ Moreover, in the Glycemic Effect in Diabetes Mellitus: CarvedilolMetoprolol Comparison in Hypertensives (GEMINI) study, the occurrence and perceived burden of diabetes-related symptoms was lower with carvedilol than with metoprolol tartrate in patients already taking an ACEI or ARB in addition to diabetes and lipid-lowering therapies. ${ }^{45}$ Half of the patients required additional BP-lowering agents, starting with a diuretic. Improvements in symptom burden observed in GEMINI added to the established efficacy and tolerability profile of carvedilol, and support its continued use in patients with hypertension and diabetes. AACE recognizes the benefit of the vasodilating properties of carvedilol and nebivolol and has suggested that these agents may be beneficial in patients with hypertension and diabetes. ${ }^{9}$

The third-generation $\beta$-blockers such as labetalol, carvedilol, and nebivolol reduce BP in part through lowering peripheral vascular resistance (vasodilation) instead of reducing cardiac output as done by the older, traditional $\beta$-blockers. ${ }^{46}$ The vasodilatory action of labetalol, carvedilol, and nebivolol may lessen the incidence of some adverse events associated with traditional $\beta$-blockers. For example, peripheral vasodilation may reduce the incidence of cold extremities and lessen the effect on glucose metabolism. ${ }^{47,48}$

Noncompliance with antihypertensive medications is common and is a major cause of inadequate BP control. ${ }^{49}$ Polypharmacy is one common reason for medication nonadherence, but a recent study of patients with diabetes taking an average of 4.1 medications found that unreported side effects were also responsible for selective noncompliance..$^{50}$ $\beta$-blockers have been associated with many adverse effects, including worsening glycemic control, fatigue, cold extremities, and sexual dysfunction. Studies have reported that physicians perceive $\beta$-blockers to be less well tolerated than the other three antihypertensive classes of drugs, a point of view that is bolstered by studies such as the Losartan Intervention for Endpoint Reduction (LIFE) trial and can influence prescription preferences. ${ }^{51,52}$ However, a number of randomized controlled 
trials show that $\beta$-blockers and diuretics are equally or better tolerated than ACEIs or CCBs. ${ }^{19,20,24,53-55}$

\section{Adherence in hypertension}

The clinical benefits provided by $\beta$-blockers are only effective if patients adhere to medication treatment correctly and on a long-term basis. Many factors may contribute to poor medication adherence, but side effect profiles of drugs and the complexity of dosing regimens are likely to be major factors. Reducing pill burden by prescribing a once-daily agent (although not studied specifically in $\beta$-blocker trials) has been shown to increase adherence, including in patients with hypertension. ${ }^{56}$

In a large-scale study of medication adherence among 2,325 patients with hypertension, only $39 \%$ of patients maintained therapy with one or more antihypertensive drugs throughout the 10-year followup period. ${ }^{57}$ Approximately $22 \%$ of patients temporarily stopped and restarted treatment, and 39\% stopped treatment permanently. More patients starting on diuretics and $\beta$-blockers stopped treatment (odds ratio $[\mathrm{OR}]=1.15 ; 95 \% \mathrm{CI}=0.87,1.52$ ) compared with those starting on dihydropyridine calcium antagonists $(\mathrm{OR}=0.54 ; 95 \% \mathrm{CI}=0.34,0.84)$ and $\mathrm{ACEIs}(\mathrm{OR}=0.38 ; 95 \%$ $\mathrm{CI}=0.27,0.55)$. Patients also showed higher persistence when started on combination therapy $(\mathrm{OR}=0.29 ; 95 \% \mathrm{CI}=0.14$, 0.54 compared with diuretics) or when initially treated by a cardiologist $(\mathrm{OR}=0.82 ; 95 \% \mathrm{CI}=0.61,0.97)$ or internist $(\mathrm{OR}=0.80 ; 95 \% \mathrm{CI}=0.62,0.98)$ compared with a general practitioner. ${ }^{57}$ Two factors in patient adherence to medication are the perceived symptoms and the perception of the therapy importance. It is important that the side effects of prescribed therapies are not worse than the disease symptoms, and that dosing instructions are as simple as possible for patients taking numerous medications. This is particularly problematic in the treatment of hypertension, because some medications may produce more adverse symptoms than the disease itself. ${ }^{58}$ Low compliance rates are prevalent in these patients. ${ }^{59}$ Patients with hypertension who have uncontrolled BP as a result of their poor medication-taking behavior remain at risk for serious morbidity and mortality (eg, stroke, myocardial infarction, and kidney failure). Patients with diabetes and comorbid hypertension and/or dyslipidemia are at particularly high risk for nonadherence because of the polypharmacy required to treat hyperglycemia, hypertension, and/or hyperlipidemia.

In a study of compliance with prescribed medications in 357 patients seen by family practice physicians and internists, the rates of adherence in both patients with HF $(n=123)$ and patients with diabetes $(\mathrm{n}=234)$ was less than optimal. ${ }^{60}$
Patients were taking up to 14 different drugs, and an association was observed between the number of drugs and medication-taking errors, including omission (proportion of drugs prescribed by the physician that the patient was not taking), commission (proportion of prescription drugs the patient was taking that the physician had not prescribed), scheduling misconception (proportion of prescribed drugs taken by the patient for which the patient did not know the correct schedule), and scheduling noncompliance (proportion of prescribed drugs taken by the patient for which the patient knew the correct schedule but did not take as prescribed). When all types of medication-taking errors were combined, the average total error rate was $58 \%$. Error rates for both commission and scheduling misconception errors increased as the complexity of the regimen (as measured by dosing frequency) increased. ${ }^{60}$

Reducing pill burden by prescribing a once-daily agent may increase adherence, as shown in a systemic review of hypertension studies in which the highest adherence was found with once-daily dosing and declined as the daily dose frequency increased. ${ }^{56}$ To improve outcomes among patients with hypertension, programs to detect poor medication adherence and support long-term persistence must be developed and successfully implemented, using antihypertensive agents that promote and aid adherence through simplified dosing and high tolerability. ${ }^{61}$

\section{Choosing $\beta$-blockers for optimal treatment of high-risk hypertensive patients Atenolol}

In clinical studies, especially the studies evaluated in recent meta-analyses, atenolol $50 \mathrm{mg}$ to $100 \mathrm{mg}$ is typically a once-daily therapy. ${ }^{41,62-64}$ However, this atenolol regimen may not provide a full 24 hours of blood pressure control. This is illustrated by a small, open-label study involving 36 patients with hypertension who were receiving hydrochlorothiazide $12.5 \mathrm{mg}$, whereby adding $50 \mathrm{mg}$ atenolol or metoprolol succinate once daily in the morning (force-titrated to $100 \mathrm{mg}$ at four weeks) provided lowered systolic blood pressures (SBP) during the midnight to six o'clock hours with metoprolol tartrate $(-7 \mathrm{mmHg})$, but not atenolol $(3 \mathrm{mmHg}$; $P=0.03) \cdot{ }^{65}$ Additionally, in another study of atenolol (50 to $100 \mathrm{mg}$ once daily), the decrease in diastolic blood pressure (DBP) values in the last six hours of the 24-hour dosing period was significantly less than in the previous 18 hours $(P<0.01) .{ }^{66}$ Night time and early morning BP control is 
important because it is during these times that increases in cardiovascular morbidity are observed..$^{65}$ The results of these studies may explain, in part, the reduced benefit regarding cardiovascular events attributed to $\beta$-blockers (primarily atenolol) compared with other antihypertensive agents in the previously mentioned meta-analysis. ${ }^{41}$ Moreover, delaying an atenolol dose may have clinically relevant effects on BP control.

Atenolol was also found to decrease insulin sensitivity and increase triglyceride levels and risk of new-onset diabetes compared with other antihypertensive classes in two large studies. ${ }^{67-69}$ In patients at high risk for diabetes or dyslipidemia or who develop these conditions, atenolol may not be appropriate.

\section{Metoprolol}

Metoprolol is a relatively $\beta 1$-adrenergic receptor selective agent, but loses this selectivity at higher plasma concentrations. ${ }^{70}$ This agent has two formulations; an immediaterelease (tartrate) and an extended-release (succinate). ${ }^{71}$ The immediate-release formulation is a twice-daily regimen, because at $100 \mathrm{mg}$ once daily, metoprolol tartrate does not provide clinically relevant $\beta 1$-adrenergic receptor blockade (assessed by exercised-induced tachycardia) in the last six hours of the 24-hour dosing period..$^{71}$ Additionally, maximum plasma concentrations have been shown to be as much as four-fold higher with the immediate-release formulation compared with the extended-release formulation at 100 mg. ${ }^{71}$ If patients with hypertension are unable to tolerate metoprolol tartrate, a recommended alternative treatment endorsed by pharmacists is metoprolol succinate at the total daily metoprolol tartrate dose. ${ }^{72}$ If metoprolol succinate is not tolerated, another $\beta$-blocker such as carvedilol or bisoprolol can be started 24 hours after the last metoprolol dose (see later for carvedilol dosing equivalence and see Table 3). ${ }^{72}$

\section{Labetalol}

Labetalol was the first $\beta$-blocker to provide comprehensive adrenergic blockade. ${ }^{73}$ However, because of a short half-life (six to eight hours), labetalol is administered as a twice-daily medication and is not as convenient as once-daily dosing for patients with hypertension who are taking multiple medications. ${ }^{73}$ A key property of labetalol is that it lowers BP quickly (orally, within two hours; intravenously, in 10 minutes) and in a steady manner without clinically relevant changes in heart rate or cardiac output. ${ }^{73}$ Therefore, labetalol is ideally suited for use in hypertensive emergencies. ${ }^{74}$ Labetalol has also been found to be useful in the treatment of hypertension during pregnancy, especially severe hypertension, given that ACEIs and ARBs are contraindicated because of adverse effects. $^{75}$

Labetalol has been well tolerated in general practice in patients with all stages of hypertension. A review of 11 general practice studies involving 8573 patients reported that tiredness, dizziness, headache, and upper gastrointestinal symptoms were the most common adverse events during labetalol treatment. ${ }^{76}$ Moreover, except for headache, patients treated with labetalol $400 \mathrm{mg}$ reported fewer of the common adverse events compared with propranolol and slow-release oxprenolol. However, the incidence of adverse events during labetalol treatment appeared to be dose-dependent. No published reports were found with labetalol in patients with diabetes or other conditions with a high risk of cardiovascular events. Nevertheless, in 81 patients with severe hypertension who received either labetalol-based or methyldopa-based therapy for up to one year, labetalol-based therapy provided hypertension control (diastolic BP $<90 \mathrm{mmHg}$ ) in $40 \%$ of patients, with nausea being the most commonly reported adverse event. ${ }^{77}$

\section{Nebivolol}

Nebivolol $5 \mathrm{mg}$ is administered once daily and has been shown in clinical trials to be well tolerated in patients with hypertension, although there is no indication for ts use after an MI or in patients with HF. A recent open-label, six-week study of nebivolol (5 to $10 \mathrm{mg}$ daily) in patients with mild hypertension $(n=6356)$ reported no serious adverse events and only $0.5 \%$ of patients reported any adverse event. ${ }^{78}$ In a meta-analysis of 12 studies involving 2653 patients with hypertension, the adverse events reported for nebivolol $5 \mathrm{mg}$ were higher than placebo $(\mathrm{OR}=1.16 ; 95 \% \mathrm{CI}$, $0.76-1.67 ; P=0.482)$ but lower than other antihypertensive agents combined (ACEIs, ARBs, CCBs, atenolol, metoprolol tartrate, and bisoprolol; $\mathrm{OR}=0.59 ; 95 \% \mathrm{CI}, 0.48-0.72$; $P<0.001) .{ }^{79}$ In a three-month, open-label study in 2838 patients with hypertension and Type 2 diabetes, nebivolol ( 2.5 to $10 \mathrm{mg}$ daily) lowered BP to the recommended goal $(<130 / 80 \mathrm{mmHg})$ in $9.6 \%$ of patients and to a diastolic BP of $\leq 90 \mathrm{mmHg}$ in $88 \%$ of patients. ${ }^{44}$ There was a small increase in physical capabilities that achieved statistical significance $(P<0.001)$. Reported adverse events were low, comprising $0.3 \%$ of patients, with headache, fatigue, and nausea each reported in one patient. At study entry, approximately $40 \%$ of patients were receiving ACEIs and $20 \%$ were receiving an ARB. 
Compared with atenolol $50 \mathrm{mg}$ daily in patients with hypertension $(\mathrm{n}=366)$, nebivolol $5 \mathrm{mg}$ daily reduced the number of patients who reported fatigue (eight versus four, respectively).$^{80}$ However, a similar number of patients reported dizziness (two versus three, respectively) and headache (four versus three, respectively). It has been reported in a recent review that similar results were obtained from a clinical trial comparing nebivolol with metoprolol. ${ }^{81}$

\section{Carvedilol CR}

The availability of carvedilol controlled-release (carvedilol $\mathrm{CR}$ ), a once-daily formulation of carvedilol, allows for the choice of a $\beta$-blocker that does not have adverse effects on glycemic control and is also convenient for patients. Carvedilol CR was approved by the US Food and Drug Administration (FDA) with the same indications as the original twice-daily formulation (hypertension, post-MI with left ventricular dysfunction, and HF). ${ }^{82}$ When prescribing any new medication, the discussion of adverse events (side effects) is important because it may be a barrier to patient adherence. Carvedilol CR has been well tolerated in the clinical trials conducted so far in patients with hypertension and with left ventricular dysfunction. ${ }^{83,84}$ In patients with uncomplicated hypertension, carvedilol CR was tolerated without an increase in total adverse events at the highest dose (80 mg once daily) compared with placebo. ${ }^{85}$

Recent studies have shown that carvedilol CR is effective in lowering BP. In a randomized, placebo-controlled study that compared three doses of carvedilol CR (20, 40, and $80 \mathrm{mg}$ once daily) with placebo in patients with essential hypertension, the 24-hour DBP fell in the placebo group and the three carvedilol CR groups $(P \leq 0.001$, trend for all carvedilol CR doses compared with placebo). ${ }^{85}$ The mean SBP reduction at peak dose with carvedilol CR $80 \mathrm{mg}$ was $-15.3 \mathrm{mmHg} .{ }^{86}$

\section{Dosing equivalence of carvedilol and carvedilol CR}

Carvedilol CR has been shown to be therapeutically equivalent to carvedilol, but with the benefit of once-daily dosing. A number of investigations demonstrated that the pharmacokinetic and pharmacodynamic properties are equivalent between twice-daily carvedilol and oncedaily carvedilol CR; the two formulations were shown to be equivalent in all doses used in hypertension. ${ }^{87}$ For hypertension treatment, carvedilol $\mathrm{CR}$ is available at doses of 10, 20,40, and $80 \mathrm{mg}$; the equivalent carvedilol doses
Table 2 Recommended algorithm for replacing carvedilol with carvedilol $C R$ in patients with hypertension

\begin{tabular}{|c|c|c|}
\hline Current dose of carvedilol & & $\begin{array}{l}\text { Starting dose of } \\
\text { carvedilol } \mathbf{C R}^{\mathrm{b}}\end{array}$ \\
\hline $6.25 \mathrm{mg}(3.125 \mathrm{mg}$ BID) & Wait 12 hours $^{a}$ & $10 \mathrm{mg}$ QD \\
\hline $12.5 \mathrm{mg}$ (6.25 mg BID) & & $20 \mathrm{mg}$ QD \\
\hline 25 mg (I2.5 mg BID) & & $40 \mathrm{mg}$ QD \\
\hline 50 mg (25 mg BID) & & $80 \mathrm{mg}$ QD \\
\hline
\end{tabular}

Notes: aSuggestion for patients: Take the nighttime dose of carvedilol BID and start carvedilol CR the next morning. 'When switching from carvedilol $12.5 \mathrm{mg}$ or $25 \mathrm{mg}$ BID, a lower starting dose of $\mathrm{COREG}^{\circledR} \mathrm{CR}$ may be considered for elderly patients ( $\geq 65$ years) or those at increased risk of hypotension, dizziness, or syncope. Subsequent titration to higher doses should, as appropriate, be made after an interval of at least two weeks. Recommendations are based on the author's opinion, Coreg CR prescribing information, ${ }^{82}$ and data from Fonarow. ${ }^{88}$

Abbreviations: $\mathrm{BID}$, twice daily; $\mathrm{CR}$, controlled release; $\mathrm{QD}$, once daily.

are shown in Table $2 .^{82,88}$ It is the author's opinion, based on Fonarow et al, ${ }^{88}$ that most patients currently on a stable carvedilol dose should start the equivalent carvedilol CR dose the day following their last evening dose of carvedilol. However, a recent update to the carvedilol CR prescribing information suggests that when switching from carvedilol $12.5 \mathrm{mg}$ or $25 \mathrm{mg}$ twice daily, a lower starting dose of carvedilol CR may be considered for elderly patients ( $\geq 65$ years) or those at increased risk of hypotension, dizziness, or syncope. Subsequent titration to higher doses should, as appropriate, be made after an interval of at least two weeks.

\section{Dose equivalence of other $\beta$-blockers and carvedilol CR}

It is important to understand dose equivalence among $\beta$-blockers for the selection of an optimal regimen in patients with changing and complex needs, especially in patients who develop dyslipidemia or diabetes. The dose equivalencies shown in Table 3 are based on clinical experience and were chosen to maintain similar BP lowering levels. Replacing another $\beta$-blocker with carvedilol CR is generally safe and well tolerated, but patients should be monitored to ensure medication compliance, degree of BP lowering, and tolerance. Possible adverse events associated with $\alpha$-blockade are dizziness and postural hypotension.

The recommended starting dose of carvedilol CR in patients with hypertension is $20 \mathrm{mg}$ once daily. Although the prescribing information for carvedilol CR states that uptitration should occur at one to two week intervals, it is the author's opinion that in situations where carvedilol CR is replacing another $\beta$-blocker, uptitration should occur at 
Table 3 Suggested dose equivalences between other $\beta$-blockers and carvedilol CR in hypertension

\begin{tabular}{|c|c|c|c|}
\hline \multirow[t]{2}{*}{ Current $\beta$-blocker } & & \multicolumn{2}{|l|}{ Carvedilol CR } \\
\hline & & Starting dose $\mathrm{e}^{\mathrm{a}}$ & $\begin{array}{l}\text { Uptitration (after several days } \\
\text { to one week) as tolerated }\end{array}$ \\
\hline Atenolol & & Carvedilol CR & Carvedilol CR \\
\hline $50 \mathrm{mg} \mathrm{QD}^{c}$ & Wait 24 hours from last dose & 20 mg QD & 40 mg QD \\
\hline$\geq 75 \mathrm{mg}$ QD & of once-daily atenolol & $40 \mathrm{mg}$ QD & $80 \mathrm{mg}$ QD \\
\hline \multicolumn{4}{|c|}{ Metoprolol tartrate } \\
\hline $25-50 \mathrm{mg}$ BID & Wait 12 hours from last dose & $20 \mathrm{mg}$ QD & 40 mg QD \\
\hline 75-100 mg BID & of metoprolol tartrate & $40 \mathrm{mg}$ QD & $80 \mathrm{mg}$ QD \\
\hline$>100 \mathrm{mg}$ BID & & 40-80 mg QD & 80 mg QD \\
\hline \multicolumn{4}{|c|}{ Metoprolol succinate } \\
\hline 50-100 mg QD & Wait 24 hours from last dose & $20 \mathrm{mg}$ QD & 40 mg QD \\
\hline I50-200 mg QD & of metoprolol succinate & $40 \mathrm{mg}$ QD & $80 \mathrm{mg}$ QD \\
\hline$>200 \mathrm{mg}$ QD & & 40-80 mg QD & 80 mg QD \\
\hline
\end{tabular}

Notes: aln clinical trials, carvedilol CR was initiated in $\beta$-blocker-naive patients at $20 \mathrm{mg}$. The recommendations in this table are based on the author's clinical and research experience and, therefore, recommend switching patients already on a medium to high dose of another $\beta$-blocker to a medium to high dose of carvedilol CR.A caveat, however: older patients ( $>65$ years), patients with diabetic neuropathy, or those predisposed to orthostatic hypotension should generally start at 20 mg if on a low dose of another $\beta$-blocker and $40 \mathrm{mg}$ if on a high dose of another $\beta$-blocker. Such patients may then be uptitrated as tolerated; switching directly to $80 \mathrm{mg}$ is not recommended in these patients. Physicians should closely monitor all patients to avoid possible worsening of BP and increases in heart rate after switching to 20 or 40 mg of carvedilol CR, which would call for a quicker uptitration. 'Uptitrate to achieve BP goal. Maximal dose is $80 \mathrm{mg}$ daily (equivalent to $25 \mathrm{mg}$ of carvedilol BID). clf patients are on a dose of atenolol lower than $50 \mathrm{mg}$ (ie, $25 \mathrm{mg} /$ day) it is unclear what the exact dose of carvedilol CR would be; however, patients at this low a dose should not be started on a dose higher than $20 \mathrm{mg}$ of carvedilol CR.

Notes: Physicians should be guided by their own judgment and experience in choosing doses when switching between drugs.

Abbreviations: BID, twice daily; QD, once daily.

two- to three-day intervals as tolerated. Before prescribing carvedilol, all other medications should be stable. Other agents with vasodilatory properties (such as CCBs, nitrates, or other antihypertensives) should not be added to the patient's regimen immediately before or during the adjustment period.

\section{Conclusions}

Hypertension is the most common diagnosis in the primary care setting and can only be treated properly if the patient adheres to the medication regimen. In general, adherence to antihypertensive drugs is suboptimal and may be further decreased by complicated drug regimens. Choice of antihypertensive therapy is a contributing factor to both medication adherence and clinical outcomes. Even within a single antihypertensive class, such as the $\beta$-blockers, the clinical profile of the members may vary greatly. Consequently, information about the dosing, efficacy, tolerability, and pharmacokinetic properties of the various agents is necessary in order to select the $\beta$-blocker that is most appropriate for the individual patient. Although all $\beta$-blockers are effective in reducing BP, they have very different hemodynamic, tolerability, and metabolic profiles. The earlier $\beta$-blockers, atenolol and metoprolol, may require a twice-daily regimen and may result in glucose and lipid metabolism abnormalities. Nebivolol is a once-daily $\beta$-blocker for the treatment of hypertension with neutral metabolic properties; however, it is not indicated after an MI or if a patient progresses to HF. The availability of carvedilol CR, a once-daily formulation of carvedilol, will result in an easier dosing regimen while retaining the neutral metabolic properties that make carvedilol a desirable agent in high-risk patients with hypertension.

\section{Acknowledgments}

Editorial assistance, specifically revisions to the final draft, was provided by Tamalette Loh, $\mathrm{PhD}$, at ProEd Communications, Inc. ${ }^{\circledR}$, whose services were also funded by GlaxoSmithKline. Dr Loh's revisions were reviewed and approved by Dr McGill.

\section{Disclosures}

Dr McGill is a consultant for GlaxoSmithKline and a speaker for AstraZeneca and Forest Pharmaceuticals. Financial support for medical editorial assistance was provided by GlaxoSmithKline, Philadelphia, Pennsylvania.

\section{References}

1. Cherry DK, Woodwell DA. National Ambulatory Medical Care Survey: 2000 summary. Adv Data. 2002;(328):1-32.

2. Hypertension in America: A national reading. Am J Manag Care. 2005;11(13 Suppl):S383-S385. 
3. Ong KL, Cheung BM, Man YB, Lau CP, Lam KS. Prevalence, awareness, treatment, and control of hypertension among United States adults 1999-2004. Hypertension. 2007;49(1):69-75.

4. Moser M. Evolution of the treatment of hypertension from the 1940s to JNC V. Am J Hypertens. 1997;10(3):2S-8S.

5. Chobanian AV, Bakris GL, Black HR, et al. Seventh report of the Joint National Committee on Prevention, Detection, Evaluation, and Treatment of High Blood Pressure. Hypertension. 2003;42(6): 1206-1252.

6. Bakris GL. The importance of blood pressure control in the patient with diabetes. Am J Med. 2004;116 Suppl 5A:30S-38S.

7. Tight blood pressure control and risk of macrovascular and microvascular complications in type 2 diabetes: UKPDS 38. UK Prospective Diabetes Study Group. BMJ. 1998;317(7160):703-713.

8. Efficacy of atenolol and captopril in reducing risk of macrovascular and microvascular complications in type 2 diabetes: UKPDS 39. UK Prospective Diabetes Study Group. BMJ. 1998;317(7160):713-720.

9. Torre JJ, Bloomgarden ZT, Dickey RA, et al. American Association of Clinical Endocrinologists Medical Guidelines for Clinical Practice for the diagnosis and treatment of hypertension. Endocr Pract. 2006;12(2):193-222.

10. American Diabetes Association. Standards of medical care in diabetes. Diabetes Care. 2005;28(Suppl 1):S4-S36.

11. Bakris GL, Williams M, Dworkin L, et al. Preserving renal function in adults with hypertension and diabetes: A consensus approach. National Kidney Foundation Hypertension and Diabetes Executive Committees Working Group. Am J Kidney Dis. 2000;36(3):646-661.

12. Doroodchi H, Abdolrasulnia M, Foster JA, et al. Knowledge and attitudes of primary care physicians in the management of patients at risk for cardiovascular events. BMC Fam Pract. 2008;9:42.

13. Saydah SH, Fradkin J, Cowie CC. Poor control of risk factors for vascular disease among adults with previously diagnosed diabetes. JAMA. 2004;291(3):335-342.

14. Black HR, Elliott WJ, Neaton JD, et al. Baseline characteristics and early blood pressure control in the CONVINCE trial. Hypertension. 2001;37(1):12-18

15. Cooper-DeHoff RM, Handberg EM, Cohen J, et al. Characteristics of contemporary patients with hypertension and coronary artery disease. Clin Cardiol. 2004;27(10):571-576.

16. Hajjar I, Kotchen TA. Trends in prevalence, awareness, treatment, and control of hypertension in the United States, 1988-2000. JAMA. 2003;290(2):199-206.

17. Snow V, Weiss KB, Mottur-Pilson C. The evidence base for tight blood pressure control in the management of type 2 diabetes mellitus. Ann Intern Med. 2003;138(7):587-592.

18. Arauz-Pacheco C, Parrott MA, Raskin P. Treatment of hypertension in adults with diabetes. Diabetes Care. 2003;26(Suppl 1):S80-S82.

19. Hansson L, Hedner T, Lund-Johansen P, et al. Randomised trial of effects of calcium antagonists compared with diuretics and beta-blockers on cardiovascular morbidity and mortality in hypertension: The Nordic Diltiazem (NORDIL) study. Lancet. 2000;356(9227):359-365.

20. Brown MJ, Palmer CR, Castaigne A, et al. Morbidity and mortality in patients randomised to double-blind treatment with a long-acting calcium-channel blocker or diuretic in the International Nifedipine GITS study: Intervention as a Goal in Hypertension Treatment (INSIGHT). Lancet. 2000;356(9227):366-372.

21. Hansson L, Lindholm LH, Niskanen L, et al. Effect of angiotensinconverting-enzyme inhibition compared with conventional therapy on cardiovascular morbidity and mortality in hypertension: The Captopril Prevention Project (CAPPP) randomised trial. Lancet. 1999;353(9153):611-616.

22. Carlberg B, Samuelsson O, Lindholm LH. Atenolol in hypertension: Is it a wise choice? Lancet. 2004;364(9446):1684-1689.

23. Law MR, Wald NJ, Morris JK, Jordan RE. Value of low dose combination treatment with blood pressure lowering drugs: Analysis of 354 randomised trials. BMJ. 2003;326(7404):1427.
24. Neaton JD, Grimm RH Jr, Prineas RJ, et al; Treatment of Mild Hypertension Study. Final results. Treatment of Mild Hypertension Study Research Group. JAMA. 1993;270(6):713-724.

25. Materson BJ, Reda DJ, Cushman WC. Department of Veterans Affairs single-drug therapy of hypertension study. Revised figures and new data. Department of Veterans Affairs Cooperative Study Group on Antihypertensive Agents. Am J Hypertens. 1995;8(2):189-192.

26. Tse WY, Kendall M. Is there a role for beta-blockers in hypertensive diabetic patients? Diabet Med. 1994;11(2):137-144.

27. Fonarow GC. Managing the patient with diabetes mellitus and heart failure: Issues and considerations. Am J Med. 2004;116 Suppl 5A:76S-88S.

28. Bell DS. Use of beta blockers in the patient with diabetes. Endocrinologist. 2003;13(2):116-123.

29. A randomized trial of propranolol in patients with acute myocardial infarction. I. Mortality results. JAMA. 1982;247(12):1707-1714.

30. CIBIS-II Investigators and Committees. The Cardiac Insufficiency Bisoprolol Study II (CIBIS-II): A randomised trial. Lancet. 1999;353(9146):9-13.

31. Dargie HJ. Effect of carvedilol on outcome after myocardial infarction in patients with left ventricular dysfunction: The CAPRICORN randomised trial. Lancet. 2001;357(9266):1385-1390.

32. Major cardiovascular events in hypertensive patients randomized to doxazosin vs. chlorthalidone: The antihypertensive and lipid-lowering treatment to prevent heart attack trial (ALLHAT). ALLHAT Collaborative Research Group. JAMA. 2000;283(15):1967-1975.

33. Majumdar SR. Beta-blockers for the treatment of hypertension in patients with diabetes: Exploring the contraindication myth. Cardiovasc Drugs Ther. 1999;13(5):435-439.

34. Haenni A, Lithell H. Treatment with a beta-blocker with beta 2-agonism improves glucose and lipid metabolism in essential hypertension. Metabolism. 1994;43(4):455-461.

35. Bakris GL, Fonseca V, Katholi RE, et al. Metabolic effects of carvedilol vs. metoprolol in patients with type 2 diabetes mellitus and hypertension: A randomized controlled trial. JAMA. 2004;292(18):2227-2236.

36. Bristow MR. Mechanism of action of beta-blocking agents in heart failure. Am J Cardiol. 1997;80(11A):26L-40L.

37. Bristow MR. Beta-adrenergic receptor blockade in chronic heart failure. Circulation. 2000;101(5):558-569.

38. Packer M. Beta-adrenergic blockade in chronic heart failure: Principles, progress, and practice. Prog Cardiovasc Dis. 1998;41(1 Suppl 1):39-52.

39. Poole-Wilson PA, Swedberg K, Cleland JG, et al. Comparison of carvedilol and metoprolol on clinical outcomes in patients with chronic heart failure in the Carvedilol Or Metoprolol European Trial (COMET): Randomised controlled trial. Lancet. 2003;362(9377):7-13.

40. Wikstrand J, Berglund G, Tuomilehto J. Beta-blockade in the primary prevention of coronary heart disease in hypertensive patients. Review of present evidence. Circulation. 1991;84(6 Suppl):VI93-VI100.

41. Lindholm LH, Carlberg B, Samuelsson O. Should beta blockers remain first choice in the treatment of primary hypertension? A meta-analysis. Lancet. 2005;366(9496):1545-1553.

42. Jacob S, Rett K, Wicklmayr M, Agrawal B, Augustin HJ, Dietze GJ. Differential effect of chronic treatment with two beta-blocking agents on insulin sensitivity: The carvedilol-metoprolol study. $J$ Hypertens. 1996;14(4):489-494.

43. Giugliano D, Acampora R, Marfella R, et al. Metabolic and cardiovascular effects of carvedilol and atenolol in non-insulin-dependent diabetes mellitus and hypertension. A randomized, controlled trial. Ann Intern Med. 1997;126(12):955-959.

44. Schmidt AC, Graf C, Brixius K, Scholze J. Blood pressure-lowering effect of nebivolol in hypertensive patients with type 2 diabetes mellitus: The YESTONO study. Clin Drug Investig. 2007;27(12):841-849.

45. McGill JB, Bakris GL, Fonseca V, et al. Beta-blocker use and diabetes symptom score: Results from the GEMINI study. Diabetes Obes Metab. 2007;9(3):408-417.

46. Pedersen ME, Cockcroft JR. The vasodilatory beta-blockers. Curr Hypertens Rep. 2007;9(4):269-277. 
47. Stolwijk JA. Responses to the thermal environment. Fed Proc. 1977;36(5):1655-1658.

48. Messerli FH, Grossman E. Beta-blockers in hypertension: Is carvedilol different? Am J Cardiol. 2004;93(9A):7B-12B.

49. Yiannakopoulou E, Papadopulos JS, Cokkinos DV, Mountokalakis TD. Adherence to antihypertensive treatment: A critical factor for blood pressure control. Eur J Cardiovasc Prev Rehabil. 2005;12(3):243-249.

50. Grant RW, Devita NG, Singer DE, Meigs JB. Polypharmacy and medication adherence in patients with type 2 diabetes. Diabetes Care. 2003;26(5):1408-1412.

51. Ubel PA, Jepson C, Asch DA. Misperceptions about beta-blockers and diuretics: A national survey of primary care physicians. J Gen Intern Med. 2003;18(12):977-983.

52. Dahlof B, Devereux RB, Kjeldsen SE, et al. Cardiovascular morbidity and mortality in the Losartan Intervention For Endpoint reduction in hypertension study (LIFE): A randomised trial against atenolol. Lancet. 2002;359(9311):995-1003.

53. Materson BJ, Reda DJ, Cushman WC, et al. Single-drug therapy for hypertension in men. A comparison of six antihypertensive agents with placebo. The Department of Veterans Affairs Cooperative Study Group on Antihypertensive Agents. $N$ Engl J Med. 1993;328(13): 914-921.

54. Croog SH, Levine S, Testa MA, et al. The effects of antihypertensive therapy on the quality of life. $N$ Engl J Med. 1986;314(26) 1657-1664.

55. Ogihara T, Kuramoto K. Effect of long-term treatment with antihypertensive drugs on quality of life of elderly patients with hypertension: A double-blind comparative study between a calcium antagonist and a diuretic. NICS-EH Study Group. National Intervention Cooperative Study in Elderly Hypertensives. Hypertens Res. 2000;23(1): 33-37.

56. Claxton AJ, Cramer J, Pierce C. A systematic review of the associations between dose regimens and medication compliance. Clin Ther. 2001;23(8):1296-1310.

57. Van Wijk BL, Klungel OH, Heerdink ER, de Boer A. Rate and determinants of 10 -year persistence with antihypertensive drugs. J Hypertens. 2005;23(11):2101-2107.

58. Mena-Martin FJ, Martin-Escudero JC, Simal-Blanco F, CarreteroAres JL, Arzua-Mouronte D, Herreros-Fernandez V. Health-related quality of life of subjects with known and unknown hypertension: Results from the population-based Hortega study. J Hypertens. 2003;21(7): 1283-1289.

59. Cheng JW, Kalis MM, Feifer S. Patient-reported adherence to guidelines of the Sixth Joint National Committee on Prevention, Detection, Evaluation, and Treatment of High Blood Pressure. Pharmacotherapy. 2001;21(7):828-841.

60. Hulka BS, Cassel JC, Kupper LL, Burdette JA. Communication, compliance, and concordance between physicians and patients with prescribed medications. Am J Public Health. 1976;66(9):847-853.

61. Burnier M. Medication adherence and persistence as the cornerstone of effective antihypertensive therapy. Am J Hypertens. 2006;19(11):1190-1196

62. Bangalore S, Parkar S, Grossman E, Messerli FH. A meta-analysis of 94,492 patients with hypertension treated with beta blockers to determine the risk of new-onset diabetes mellitus. Am J Cardiol. 2007;100(8):1254-1262.

63. Aursnes I, Osnes JB, Tvete IF, Gasemyr J, Natvig B. Does atenolol differ from other beta-adrenergic blockers? BMC Clin Pharmacol 2007;7:4

64. TENORMIN ${ }^{\circledR}$ (atenolol) Tablets [Prescribing information]. Wilmington, DE: AstraZeneca Pharmaceuticals LP; 2008 Available at: http://www.realmentalhealth.com/medications/tenormin.asp?view=print. Accessed November 6, 2009.

65. Sarafidis P, Bogojevic Z, Basta E, Kirstner E, Bakris GL. Comparative efficacy of two different beta-blockers on 24-hour blood pressure control. J Clin Hypertens (Greenwich). 2008;10(2):112-118.
66. Neutel JM, Schnaper H, Cheung DG, Graettinger WF, Weber MA. Antihypertensive effects of beta-blockers administered once daily: 24-hour measurements. Am Heart J. 1990;120(1):166-171.

67. Koh KK, Quon MJ, Han SH, et al. Distinct vascular and metabolic effects of different classes of anti-hypertensive drugs. Int $J$ Cardiol. 2010;140(1):73-81.

68. Gupta AK, Dahlof B, Dobson J, Sever PS, Wedel H, Poulter NR. Determinants of new-onset diabetes among 19,257 hypertensive patients randomized in the Anglo-Scandinavian Cardiac Outcomes Trial - blood pressure lowering arm and the relative influence of antihypertensive medication. Diabetes Care. 2008;31(5):982-988.

69. Olsen MH, Fossum E, Hoieggen A, et al. Long-term treatment with losartan versus atenolol improves insulin sensitivity in hypertension: ICARUS, a LIFE substudy. J Hypertens. 2005;23(4):891-898.

70. Kendall MJ, Maxwell SR, Sandberg A, Westergren G. Controlled release metoprolol. Clinical pharmacokinetic and therapeutic implications. Clin Pharmacokinet. 1991;21(5):319-330.

71. Lucker P, Moore G, Wieselgren I, Olofsson B, Bergstrand R. Pharmacokinetic and pharmacodynamic comparison of metoprolol $\mathrm{CR} / \mathrm{ZOK}$ once daily with conventional tablets once daily and in divided doses. J Clin Pharmacol. 1990;30(2 Suppl):S17-S27.

72. Alternatives for metoprolol succinate. Pharmacist's Letter/Prescriber's Letter. 2009;25(3):250-302.

73. MacCarthy EP, Bloomfield SS. Labetalol: A review of its pharmacology, pharmacokinetics, clinical uses and adverse effects. Pharmacotherapy. 1983;3(4):193-219.

74. Varon J. Treatment of acute severe hypertension: Current and newer agents. Drugs. 2008;68(3):283-297.

75. Podymow T, August P. Hypertension in pregnancy. Adv Chronic Kidney Dis. 2007;14(2):178-190.

76. Kane JA. Labetalol in general practice: A review. Br J Clin Pharmacol. 1982;13(1 Suppl):59S-63S.

77. Wallin JD, Wilson D, Winer N, et al. Treatment of severe hypertension with labetalol compared with methyldopa and furosemide. Results of a longterm, double-blind, multicenter trial. Am J Med. 1983;75(4A):87-94.

78. Cleophas TJ, Agrawal R, Lichtenthal A, Makel W, Fici F. Nationwide efficacy-safety study of nebivolol in mildly hypertensive patients. Am J Ther. 2006;13(3):192-197.

79. Van Bortel LM, Fici F, Mascagni F. Efficacy and tolerability of nebivolol compared with other antihypertensive drugs: A meta-analysis. Am J Cardiovasc Drugs. 2008;8(1):35-44.

80. Van Nueten L, Taylor FR, Robertson JI. Nebivolol vs. atenolol and placebo in essential hypertension: A double-blind randomised trial. J Hum Hypertens. 1998;12(2):135-140.

81. Cockcroft J. A review of the safety and efficacy of nebivolol in the mildly hypertensive patient. Vasc Health Risk Manag. 2007;3(6):909-917.

82. COREG $\mathrm{CR}^{\circledR}$ (carvedilol phosphate) Extended-release capsules [Prescribing information]. Research Triangle Park, NC: GlaxoSmithKline, Inc.; 2008. Available at: http://us.gsk.com/products/assets/us_coregcr.pdf. Accessed November 6, 2009.

83. Henderson LS, Tenero DM, Baidoo CA, et al. Pharmacokinetic and pharmacodynamic comparison of controlled-release carvedilol and immediate-release carvedilol at steady state in patients with hypertension. Am J Cardiol. 2006;98(7A):17L-26L.

84. Packer M, Lukas MA, Tenero DM, Baidoo CA, Greenberg BH. Pharmacokinetic profile of controlled-release carvedilol in patients with left ventricular dysfunction associated with chronic heart failure or after myocardial infarction. Am J Cardiol. 2006;98(7A): $39 \mathrm{~L}-45 \mathrm{~L}$.

85. Weber MA, Sica DA, Tarka EA, Iyengar M, Fleck R, Bakris GL. Controlled-release carvedilol in the treatment of essential hypertension. Am J Cardiol. 2006;98(7A):32L-38L.

86. Weber MA, Bakris GL, Tarka EA, Iyengar M, Fleck R, Sica DA. Efficacy of a once-daily formulation of carvedilol for the treatment of hypertension. J Clin Hypertens (Greenwich). 2006;8(12): $840-849$. 
87. Tenero DM, Henderson LS, Baidoo CA, et al. Pharmacokinetic properties of a new controlled-release formulation of carvedilol. Am J Cardiol. 2006;98(7A):5L-16L
88. Fonarow GC. Profile of carvedilol controlled-release: A new once-daily formulation of carvedilol. Expert Opin Pharmacother. 2006;7(18):2533-2546.

\section{Publish your work in this journal}

Vascular Health and Risk Management is an international, peerreviewed journal of therapeutics and risk management, focusing on concise rapid reporting of clinical studies on the processes involved in the maintenance of vascular health; the monitoring, prevention and treatment of vascular disease and its sequelae; and the involvement of metabolic disorders, particularly diabetes. This journal is indexed on PubMed Central and MedLine. The manuscript management system is completely online and includes a very quick and fair peer-review system, which is all easy to use. Visit http://www.dovepress.com/ testimonials.php to read real quotes from published authors.

Submit your manuscript here: http://www.dovepress.com/vascular-health-and-risk-management-journal 